\title{
Differences in the Effects of the Great Recession on Health Outcomes among Minority Working-Age Adults
}

\author{
Samuel D. Towne Jr. • Janice C. Probst • James W. Hardin • \\ Bethany A. Bell • Saundra Glover
}

Received: 25 April 2014 /Revised: 21 August 2014 / Accepted: 22 August 2014 /Published online: 11 September 2014 (C) W. Montague Cobb-NMA Health Institute 2014

\begin{abstract}
Introduction We examined the effects of the Great Recession (December 2007-June 2009) among vulnerable adults who may be at high risk of poor health and low access to health care.

Methods Our primary outcomes of interest were self-reported health status (fair/poor versus good/very good/excellent), and foregoing needed health care due to cost in the past 12 months.

Results Racial and ethnic minorities, except Asians, experienced higher rates of poor/fair health and higher rates of forgone medical care than did White adults. Hispanic and AIAN adults experienced differential effects of the Great Recession, as compared to White adults.
\end{abstract}

\footnotetext{
S. D. Towne Jr. $(\bowtie)$

1266 TAMU, Department of Health Promotion and Community Health Sciences, School of Public Health, Texas A\&M Health

Science Center, College Station, TX 77843-1266, USA

e-mail: towne@sph.tamhsc.edu
}

\section{J. C. Probst}

South Carolina Rural Health Research Center, University of South Carolina, 220 Stoneridge Drive, Suite 204, Columbia, SC 29210, USA

J. W. Hardin

Department of Epidemiology and Biostatistics, University of South Carolina, Columbia 29201, SC, USA

B. Bell

College of Education, Educational Psychology and Research Program, Department of Educational Studies, University of South Carolina, 133 Wardlaw, Columbia, SC 29208, USA

\section{S. Glover}

Institute for Partnerships to Eliminate Health Disparities, University of South Carolina, Discovery I, 353, 915 Greene Street, Columbia, SC 29208, USA
Conclusions Understanding how vulnerable populations react in times of economic flux will enable policy makers to identify strategies/policies to lessen the burden experienced by vulnerable adults.

Keywords Racial and ethnic minority $\cdot$ Recession $\cdot$ Health . Access to care

The sustained economic downturn of December 2007-June 2009, also known as the Great Recession (hereafter, the Recession) [1], had drastic effects on working adults. In the USA, the annual average unemployment rate, $6.0 \%$ in 2003 , rose to a high of $9.6 \%$ in 2010 [2]. Prior to the Recession, the unemployment rate for Black individuals exceeded those rates for White and Asian individuals ([3], p. 1) specifically, the unemployment rate for Black adults has consistently been double that for White adults for at least 60 years [4]. Labor force participation rates were lowest for American Indian and Alaska Native (AIAN) individuals, followed by Black individuals in 2011 [1],

The employment gap also affects one's health insurance status via employer-sponsored health insurance. Employersponsored health insurance serves as the largest source of health insurance for adults (under 65) in the USA [5]. The loss of employment may result in the loss of health insurance for millions of Americans. Among families experiencing job loss by one or more workers in 2010, $47 \%$ also reported loss of employer-sponsored health insurance [6], Before, during and after the Recession, White individuals had lower rates of being uninsured when compared to Black, Asian, and Hispanic individuals [7-9]. Being uninsured is one barrier to accessing health care, while the cost of health care is another.

The number of working age adults (ages 19-64) who reported cost-related access problems for healthcare increased from 64 million in 2005 to 75 million individuals in 2010 ([6], 
p. XII, Exhibit ES-3), Medical debt was also growing for those under 65 [10], especially in the Recession [11], where those with medical debt were also more likely to forgo needed care than those without such debt (2007-2010) [10], The number of individuals reporting having any bill problem or medical debt, was up by 15 million from 2005 to 2010 ([6], p. XII, Exhibit ES-3) These financial pressures may lead to health-related issues as well.

Financial stressors may be associated with poor quality of life for many. Persons over 50 years of age who were delinquent in their mortgage were more likely to report depressive symptoms than those not delinquent on their mortgages [12]. Unemployment has been associated with poor life evaluation, being worried and being sad during the Recession ([13], p. 16, 39-40). In addition, poor health outcomes (e.g., higher rates of diabetes and hypertension) have been shown to be higher in firms with higher rates of layoffs or downsizing [14]. In a small study in Philadelphia, individuals undergoing home foreclosure were at higher risk than others in the same community for lacking health insurance and prescription nonadherence due to cost; at the same time, Black individuals were more likely to be in the foreclosure group [15]. Historically, disparities in health, utilization and access, have been present for vulnerable populations. When compared to White populations, non-White populations in the US are more likely to report having unmet health needs, and "to forgo needed medicines" ([16], p. 1305).

Examining self-reported health status adults aged 25-74 for the years 1988-2007, Braveman and colleagues found that, when compared to White populations at any level of educational attainment, Black, Hispanic, Native Hawaiian/ Pacific Islander, and Asian populations have higher rates of below excellent/very good health status ([17], Table 2). Various measures of health (i.e., self-reported health including quality of life, depression, and having depressive symptoms) differ across racial/ethnic groups (i.e., Native American and Alaskan Native populations) [18-20].

Racial/ethnic disparities in the proportions of adults who lacked health insurance were consistent across the Recession, even as rates of insurance varied. In 2004, a greater proportion of American Indian (35\%) and Hispanic (35\%) adults under age 65 lacked health insurance than similar non-Hispanic Black (18\%), Asian (16\%), and non-Hispanic White (12\%) non-elderly adults ([21], p. 55). The proportion of persons who lack health insurance increased throughout the Recession [22].

\section{Social Determinants of Health}

The social-ecological model proposed by McLeroy et al. [23] and the conceptual framework for action on the social determinants of health proposed by Solar and
Irwin [24] both stress the importance of one's environment for health. Individual and community environmental and sociodemographic characteristics play an important role in personal health. An individual's environment includes socio-demographic characteristics of neighborhoods, or states and rurality [25].

Income, education, and employment are examples of social determinants of health that may be related to health effects in times of economic decline. Minority populations within the USA tend to fare worse in such social determinants. This is true for educational attainment ([26-28], p. 5), health literacy [29], income ([27], p. 13), and poverty rates [30]. Differences in wealth between racial and ethnic groups are closely tied to disparities in self-reported health [31]. Thus, minority adults may be at greater risk of having poor health and have greater barriers in seeking care.

\section{Purpose}

The study of past economic crises and population health during these events has been highlighted as a means to better understand and prepare for future crises [32]. We examined whether adverse economic changes from the Recession were associated with adverse changes in health care utilization and health outcomes, and whether these changes were greater among minority populations. We measured whether the Recession and subsequent recovery had differential effects on general health status and cost-related forgone medical care among non-White working-age adults, compared to White working-age adults.

\section{Methods}

Population Studied

The target population was non-institutionalized working aged adults (ages 18-64) residing in the USA between the years 2004 and 2010. Individual level information is taken from the Behavioral Risk Factor Surveillance System (BRFSS). The base number of observations, before applying inclusion criteria, for each year under study are 303,822 for 2004, 356,112 for 2005, 355,710 for 2006, 430,912 for 2007, 414,509 for 2008, 432,607 for 2009, and 451,075 for 2010 [33] (Centers for Disease Control and Prevention, 2000-2011).

We restricted samples to those aged 18-64 years of age. Only observations with complete data for race, sex, education, insurance status, employment status, place of residence (i.e., rural vs. urban), diabetes status, and disability status were retained $(1,823,347$ observations, with per-year numbers ranging from 214,633 to 287,730; see Table 1). 
Table 1 Race/ethnicity identification of working age adults, BRFSS 2004-2010, with complete data on race, sex, education, insurance status, employment status, diabetes status and disability status
Note: $n$ is not weighted for the complex sampling frame of the BRFSS

Note: Percentages are weighted for the complex sampling frame of the BRFSS

\begin{tabular}{clllllll}
\hline & 2004 & 2005 & 2006 & 2007 & 2008 & 2009 & 2010 \\
\hline Race & & & & & & & \\
Hispanic & & & & & & \\
$n$ & 15,671 & 18,396 & 18,139 & 25,033 & 22,879 & 23,150 & 24,540 \\
$\%$ & 15.16 & 15.49 & 15.69 & 16.40 & 17.17 & 16.71 & 15.95 \\
SE & 0.201 & 0.190 & 0.213 & 0.193 & 0.185 & 0.180 & 0.156 \\
AIAN & & & & & & & \\
$n$ & 3,719 & 4,478 & 4,051 & 4,862 & 4,497 & 4,522 & 4,574 \\
$\%$ & 1.13 & 1.13 & 1.18 & 1.21 & 1.09 & 1.10 & 1.15 \\
SE & 0.042 & 0.041 & 0.050 & 0.045 & 0.038 & 0.038 & 0.042 \\
Asian & & & & & & & \\
$n$ & 2,695 & 4,677 & 4,379 & 5,002 & 5,177 & 5,674 & 5,861 \\
$\%$ & 2.67 & 2.94 & 2.96 & 3.46 & 3.28 & 3.64 & 3.98 \\
SE & 0.092 & 0.086 & 0.098 & 0.102 & 0.091 & 0.099 & 0.096 \\
Black & & & & & & & \\
$n$ & 19,198 & 20,826 & 20,933 & 24,980 & 24,509 & 25,086 & 26,100 \\
$\%$ & 10.50 & 10.28 & 9.99 & 10.26 & 10.54 & 10.90 & 10.59 \\
SE & 0.124 & 0.120 & 0.126 & 0.125 & 0.126 & 0.137 & 0.115 \\
White & & & & & & & 210 \\
$n$ & 173,350 & 1995,23 & 194,706 & 227,853 & 217,419 & 217,407 & 219,481 \\
$\%$ & 70.54 & 70.17 & 70.18 & 68.67 & 67.92 & 67.65 & 68.34 \\
SE & 0.216 & 0.202 & 0.227 & 0.207 & 0.201 & 0.203 & 0.182 \\
Total & 214,633 & 247,900 & 242,208 & 287,730 & 274,481 & 275,839 & 280,556 \\
\hline
\end{tabular}

\section{Dependent Variables}

The primary outcomes of interest were general health status (fair or poor versus good, very good, or excellent) [34] and forgone medical care due to cost (time in the past 12 months when one needed to see a doctor but could not because of cost).

\section{Individual Independent Variables}

Race and ethnic categories are included in our analyses at the individual-level, and are based on the individual's reported preferred race/ethnicity category. Categories include: American Indian or Alaska Native (AIAN), White, Black or African American, Asian, and Hispanic with varying sample sizes for each year under study.

\section{Individual Level Control Variables}

Insurance status is included (2005 BRFSS codebook: "Do you have any kind of health care coverage, including health insurance, prepaid plans such as HMOs, or government plans such as Medicare") to assess differences across insurance status.

Income was coded as annual household income from all sources into categories: less than $\$ 15,000, \$ 15,000$ to less than $\$ 25,000, \$ 25,000$ to less than $\$ 35,000, \$ 35,000$ to less than $\$ 50,000, \$ 50,000$ or more, and don't know/not sure/missing.
The don't know/not sure/missing category was included in analyses to reduce the bias associated with the high rates of failing to report income in the BRFSS (approximately $13 \%$ reflecting the weighted percent taken from BRFSS codebook in 2004 and 2010).

Education was recorded in categories: did not graduate high school, graduated high school, attended college or technical school, or graduated from college or technical school.

Employment status was recorded in categories: employed (employed for wages, self-employed), unemployed (out of work for more than 1 year, out of work for less than 1 year), other (a homemaker, a student, retired, unable to work).

We included indicators of disability and diabetes status in our analysis. This reduces the effect of confounding due to the link between disease/disability status and race ([35], p. 1240). Diabetes is more prevalent among Black and AIAN individuals than all other races [36, 37]. The diabetes indicator included all respondents reporting they had diabetes, with the exception of: (1) yes, but female told only during pregnancy, (2) pre-diabetes or borderline diabetes, and (3) don't know/not sure, refused, not asked, or missing. For disability, indication was defined as the response yes versus nonindication no (not disabled), while removing from analyses responses for refused and don't know/not sure.

We used county-level information to ascertain rurality. This information was linked to our individual data via federal 
information processing standards codes (FIPS Codes) present in both the BRFSS and the Area Resource File (ARF 20102011). Urban Influence Codes (UICs) were used to identify rural/urban sub-groups. We specify UICs at 1 or 2 as urban and 3-12 as non-urban (defined as rural in the current analysis). We treat this as a fixed effect at the person-level as this classification is the same for any individual within each county and does not vary within the county. Because BRFSS public use data suppress county identifiers for lowpopulation counties with a population below 10,000 , we also include "missing" as a non-interpretable category under rurality, to reduce data loss for multivariable analysis.

\section{Contextual Control Variables}

Measures of state socio-economic characteristics related to the Recession may serve as unmeasured confounders between states. We include two state-level characteristics in our fully adjusted logistic regression models: annual poverty rates, measured at the state-level (2010-2011) [38, 39], and unemployment rate for 2004-2010 derived from the Bureau of Labor Statistics Local Area Unemployment Rates for states [40].

\section{Analysis}

We present results from bivariate and multivariate analyses. In addition to summary statistics, we use logistic regression to assess the likelihood of reporting poor/fair health (versus good, very good, or excellent) and separately reporting forgone medical care in the past 12 months due to cost (versus not). We account for the complex sampling frame of the BRFSS in all analysis using appropriate survey procedure in SAS 9.4 (SAS Institute, Cary, NC).

In all multivariable analyses, including those which assess whether differential effects of the Recession were experienced by racial and ethnic minorities as compared to Whites, we included pre-disposing and enabling factors based on our theoretical model adapted from the WHO's Conceptual Framework for Action on the Social Determinants of Health. We also included need characteristics of disability and diabetes status in the model. Our final model included individual covariates as well as state-measured annual poverty rates and unemployment rates (see Table 4). Institutional Review Board (IRB) approval was granted by the University of South Carolina.

\section{Results}

Population Characteristics and Pre-Recession Differences

Working-age adults tapped by the BRFSS were primarily White individuals followed by Black, Hispanic, Asian, and
AIAN adults (see Table 1). Table 2 highlights race-based disparities in the social determinants of health averaged across the entire study period (2004-2010). Individuals reporting the lowest income category (at below $\$ 15,000$ annual income) included a low of $4.72 \%$ for Asian adults, followed by White (6.47\%), Black (17.43\%), Hispanic (18.95\%), and AIAN adults $(19.71 \%)$. Hispanic adults were most likely to report less than a high school education $(28.77 \%)$, followed by AIAN individuals $(16.17 \%$, averaged across the study period). Hispanic adults were most likely to lack health insurance $(31.71 \%)$ followed by AIAN (27.89 \%) and Black adults $(21.41 \%)$ in comparison to White $(12.30 \%)$ and Asian adults $(10.14 \%)$. The highest rates of reporting being unemployed or having diabetes were among AIAN (11.53\% unemployment and $13.70 \%$ diabetes), followed by Black (10.31\% unemployment and $13.30 \%$ diabetes) and Hispanic (8.28 \% unemployment and $9.31 \%$ diabetes) adults (see Table 2). AIAN individuals also experienced the highest rates of disability at $28.48 \%$, averaged across the study period.

Table 3 presents self-report poor/fair health, by race and year (2004-2010). The proportion of adults reporting fair or poor health was approximately $14.00 \%$ (range 13.69 $14.21 \%$ ) throughout the study period. Asian and White individuals were least likely to report poor/fair health status across all years under study. In contrast, Hispanics and AIAN individuals had the highest rates of reporting poor/fair health status, followed by Black individuals across all years under study. Almost one in four Hispanic individuals and only a slightly lower rate of AIAN individuals reported poor/fair health status. Overall, the proportions of respondents noting poor/fair health status among Hispanic, AIAN individuals were approximately double that of White individuals.

The percentage reporting forgone medical care due to cost was approximately $15 \%$ (range $15.01-15.32 \%$ ) from 2004 to 2007, while this rate increased to approximately $16 \%$ in 2008 and approximately $17 \%$ in both 2009 and 2010 (see Table 3). Asian and White individuals had the lowest rates of reporting forgone medical care across each year of the study period, while Black, Hispanic, and AIAN individuals had the highest rates (Table 3). While this varied somewhat, approximately one in four Hispanic and AIAN adults reported forgone medical care in the past 12 months due to cost throughout the study period. In contrast, only 1 in 10 Asian or White individuals reported forgone medical care.

Multivariate Analyses

Self-Reported Health Status In fully adjusted analysis that does not include the interaction of race/ethnicity and the Recession timeline, we find that Hispanic $(\mathrm{OR}=2.12$, CI 2.045-2.194), AIAN (OR=1.42, CI 1.305-1.536), Asian $(\mathrm{OR}=1.34$, CI 1.223-1.465), and Black $(\mathrm{OR}=1.36$, CI 1.318-1.409) adults were more likely to report fair/poor health 
Table 2 Race-based differences in determinants of health status and health use, working age adults, 2004-2010 BRFSS

\begin{tabular}{|c|c|c|c|c|c|c|c|c|c|c|}
\hline & \multicolumn{2}{|l|}{ White } & \multicolumn{2}{|c|}{ African American } & \multicolumn{2}{|l|}{ Asian } & \multicolumn{2}{|l|}{ AIAN } & \multicolumn{2}{|c|}{ Hispanic } \\
\hline & $\%$ & SE & $\%$ & SE & $\%$ & SE & $\%$ & SE & $\%$ & SE \\
\hline \multicolumn{11}{|l|}{ Sex } \\
\hline Male & 39.75 & 0.041 & 31.34 & 0.114 & 42.67 & 0.270 & 40.23 & 0.280 & 36.71 & 0.121 \\
\hline Female & 60.25 & 0.041 & 68.66 & 0.114 & 57.33 & 0.270 & 59.77 & 0.280 & 63.29 & 0.121 \\
\hline \multicolumn{11}{|l|}{ Age } \\
\hline $19-43$ & 37.07 & 0.040 & 45.25 & 0.122 & 54.62 & 0.272 & 46.93 & 0.285 & 57.77 & 0.124 \\
\hline $44-64$ & 62.93 & 0.040 & 54.75 & 0.122 & 45.38 & 0.272 & 53.07 & 0.285 & 42.23 & 0.124 \\
\hline \multicolumn{11}{|l|}{ Income } \\
\hline Missing/don't know & 9.31 & 0.024 & 10.15 & 0.074 & 11.23 & 0.172 & 9.74 & 0.169 & 12.07 & 0.082 \\
\hline$<\$ 15,000$ & 6.47 & 0.020 & 17.43 & 0.093 & 4.72 & 0.116 & 19.71 & 0.227 & 18.95 & 0.099 \\
\hline$\$ 15,000-25,000$ & 10.58 & 0.026 & 21.34 & 0.101 & 8.66 & 0.154 & 22.23 & 0.237 & 24.87 & 0.109 \\
\hline$\$ 25,000-35,000$ & 9.51 & 0.024 & 13.55 & 0.084 & 8.32 & 0.151 & 12.71 & 0.190 & 12.50 & 0.083 \\
\hline$\$ 35,000-50,000$ & 15.08 & 0.030 & 13.74 & 0.085 & 12.54 & 0.181 & 13.16 & 0.193 & 11.39 & 0.080 \\
\hline$>\$ 50,000$ & 49.05 & 0.042 & 23.79 & 0.105 & 54.54 & 0.272 & 22.44 & 0.238 & 20.23 & 0.101 \\
\hline \multicolumn{11}{|l|}{ Education } \\
\hline Some high school & 5.09 & 0.018 & 12.34 & 0.081 & 3.21 & 0.096 & 16.17 & 0.210 & 28.77 & 0.114 \\
\hline High school graduate & 27.29 & 0.037 & 35.23 & 0.117 & 14.41 & 0.192 & 34.33 & 0.271 & 29.41 & 0.115 \\
\hline Some college & 28.27 & 0.037 & 27.98 & 0.110 & 19.10 & 0.215 & 30.67 & 0.263 & 21.90 & 0.104 \\
\hline College graduate & 39.35 & 0.041 & 24.45 & 0.106 & 63.28 & 0.263 & 18.83 & 0.223 & 19.91 & 0.101 \\
\hline \multicolumn{11}{|l|}{ Insurance } \\
\hline Not insured & 12.30 & 0.027 & 21.41 & 0.101 & 10.14 & 0.165 & 27.89 & 0.256 & 31.71 & 0.117 \\
\hline Insured & 87.70 & 0.027 & 78.59 & 0.101 & 89.86 & 0.165 & 72.11 & 0.256 & 68.29 & 0.117 \\
\hline \multicolumn{11}{|l|}{ Employment } \\
\hline Unemployed & 5.01 & 0.018 & 10.31 & 0.075 & 5.76 & 0.127 & 11.53 & 0.182 & 8.28 & 0.069 \\
\hline Neither employed or unemployed & 23.69 & 0.035 & 26.69 & 0.109 & 20.32 & 0.220 & 29.57 & 0.260 & 29.98 & 0.115 \\
\hline Employed & 71.30 & 0.038 & 63.00 & 0.119 & 73.92 & 0.240 & 58.90 & 0.281 & 61.74 & 0.122 \\
\hline \multicolumn{11}{|l|}{ Rurality } \\
\hline Rural & 24.57 & 0.036 & 15.32 & 0.089 & 14.27 & 0.191 & 33.76 & 0.270 & 15.28 & 0.091 \\
\hline Missing & 12.67 & 0.028 & 12.34 & 0.081 & 7.28 & 0.142 & 30.26 & 0.262 & 21.97 & 0.104 \\
\hline Metropolitan & 62.76 & 0.040 & 72.34 & 0.110 & 78.45 & 0.225 & 35.98 & 0.274 & 62.75 & 0.122 \\
\hline \multicolumn{11}{|l|}{ Disability } \\
\hline Disabled & 21.52 & 0.034 & 21.27 & 0.101 & 8.38 & 0.151 & 28.48 & 0.257 & 16.13 & 0.093 \\
\hline Not disabled & 78.48 & 0.034 & 78.73 & 0.101 & 91.62 & 0.151 & 71.52 & 0.257 & 83.87 & 0.093 \\
\hline \multicolumn{11}{|l|}{ Diabetes } \\
\hline Diabetes & 7.02 & 0.021 & 13.30 & 0.083 & 6.08 & 0.131 & 13.70 & 0.196 & 9.31 & 0.073 \\
\hline No diabetes & 92.98 & 0.021 & 86.70 & 0.083 & 93.92 & 0.131 & 86.30 & 0.196 & 90.69 & 0.073 \\
\hline
\end{tabular}

Note: Analysis is weighted for the complex sampling frame of the BRFSS

AIAN indicates American Indian/Alaska Native

status when compared to White adults. We also find that individuals in both the Recession ( $\mathrm{OR}=0.94$, CI 0.910 $0.967)$ and the Recovery $(\mathrm{OR}=0.90$, CI $0.861-0.934)$ were less likely to report fair/poor health status than those in the pre-Recession timeline, after controlling for all other terms in the model. Factors associated with a higher likelihood of reporting fair/poor health status included being poorer $(\mathrm{OR}=$ 3.43 , CI $3.290-3.571$ for less than $\$ 15,000$; $O R=2.57$, CI $2.473-2.660$ for $\$ 15,000$ to less than $\$ 25,000$; OR $=1.97$, CI
$1.893-2.047$ for $\$ 25,000$ to less than $\$ 35,000$; OR $=1.48$, CI $1.432-1.536$ for $\$ 35,000$ to less than $\$ 50,000$; all compared to the highest income category at greater than $\$ 50,000$ ), residing in a rural versus urban area $(\mathrm{OR}=1.09$, CI 1.061-1.113), having lower education than the highest level $(\mathrm{OR}=3.69$, CI $3.540-3.838$ for did not graduate high school; $\mathrm{OR}=2.04, \mathrm{CI}$ 1.975-2.096 for graduated high school; OR=1.52, CI 1.474 1.566 for attended college or technical school; all compared to graduated from college or technical school), lacking health 
Table 3 Self-reported health status and foregone care among working age adults, by race/ethnicity 2004-2010 BRFSS.

\begin{tabular}{|c|c|c|c|c|c|c|c|c|c|c|c|c|c|c|}
\hline \multirow{2}{*}{$\begin{array}{l}\text { Percent of respondents reporting: } \\
\text { Race }\end{array}$} & \multicolumn{2}{|l|}{2004} & \multicolumn{2}{|l|}{2005} & \multicolumn{2}{|l|}{2006} & \multicolumn{2}{|l|}{2007} & \multicolumn{2}{|l|}{2008} & \multicolumn{2}{|l|}{2009} & \multicolumn{2}{|l|}{2010} \\
\hline & $\%$ & SE & $\%$ & SE & $\%$ & SE & $\%$ & SE & $\%$ & SE & $\%$ & SE & $\%$ & SE \\
\hline \multicolumn{15}{|l|}{ Fair, poor health status } \\
\hline Hispanic & 26.03 & 0.007 & 25.43 & 0.006 & 24.32 & 0.007 & 25.51 & 0.007 & 22.62 & 0.005 & 22.60 & 0.005 & 22.32 & 0.005 \\
\hline AIAN & 22.88 & 0.014 & 22.87 & 0.015 & 22.31 & 0.015 & 21.74 & 0.012 & 21.90 & 0.013 & 22.97 & 0.012 & 25.63 & 0.017 \\
\hline Asian & 7.02 & 0.009 & 7.19 & 0.007 & 7.67 & 0.009 & 8.59 & 0.009 & 7.91 & 0.007 & 7.53 & 0.006 & 7.53 & 0.006 \\
\hline Black & 16.85 & 0.005 & 17.33 & 0.004 & 16.93 & 0.005 & 18.19 & 0.005 & 18.19 & 0.005 & 18.05 & 0.005 & 19.11 & 0.004 \\
\hline White & 10.30 & 0.001 & 10.89 & 0.001 & 10.60 & 0.001 & 10.94 & 0.001 & 11.06 & 0.001 & 10.87 & 0.001 & 11.10 & 0.001 \\
\hline Average, all races & 13.69 & 0.002 & 14.02 & 0.001 & 13.73 & 0.002 & 14.21 & 0.001 & 13.90 & 0.001 & 13.77 & 0.001 & 13.94 & 0.001 \\
\hline \multicolumn{15}{|l|}{ Forgoing care due to cost } \\
\hline Hispanic & 21.72 & 0.006 & 24.14 & 0.006 & 23.37 & 0.007 & 24.22 & 0.006 & 24.66 & 0.006 & 26.84 & 0.006 & 26.07 & 0.005 \\
\hline AIAN & 24.54 & 0.016 & 23.24 & 0.015 & 21.15 & 0.014 & 24.40 & 0.016 & 23.10 & 0.015 & 24.12 & 0.012 & 27.52 & 0.016 \\
\hline Asian & 11.05 & 0.011 & 10.59 & 0.009 & 10.26 & 0.011 & 10.27 & 0.010 & 12.03 & 0.013 & 12.34 & 0.011 & 12.29 & 0.008 \\
\hline Black & 20.04 & 0.005 & 19.64 & 0.005 & 19.40 & 0.005 & 20.91 & 0.005 & 21.53 & 0.005 & 23.23 & 0.006 & 23.31 & 0.005 \\
\hline White & 12.50 & 0.001 & 12.29 & 0.001 & 12.24 & 0.002 & 12.17 & 0.001 & 12.64 & 0.001 & 13.36 & 0.001 & 13.38 & 0.001 \\
\hline Average, all races & 15.07 & 0.002 & 15.26 & 0.001 & 15.01 & 0.002 & 15.32 & 0.001 & 15.93 & 0.002 & 16.96 & 0.002 & 16.76 & 0.001 \\
\hline
\end{tabular}

Note: Analysis is weighted for the complex sampling frame of the BRFSS

insurance ( $\mathrm{OR}=1.32$, CI 1.277-1.357), having a disability $(\mathrm{OR}=6.45$, CI 6.301-6.596), and having diabetes $(\mathrm{OR}=$ 3.93, CI 3.811-4.057), even after controlling for all other terms in the model.

Forgone Medical Care In fully adjusted analysis that does not include the interaction of race/ethnicity and Recession timeline, we find that Hispanic (OR=1.07, CI 1.032-1.103), AIAN (OR=1.26, CI 1.162-1.359), and Black $(\mathrm{OR}=1.15$, CI 1.116-1.186) adults were more likely to report fair/poor health status when compared to White adults. We also find that individuals in both the Recession $(\mathrm{OR}=1.11$, CI 1.079$1.143)$ and the Recovery $(\mathrm{OR}=1.11$, CI $1.066-1.153)$ were more likely to report fair/poor health status than those in the pre-Recession timeline, after controlling for all other terms in the model. Factors associated with a higher likelihood of reporting poor/fair health status included being poorer $(\mathrm{OR}=$ 3.61, CI 3.465-3.752 for less than $\$ 15,000$; OR $=3.64$, CI $3.520-3.767$ for $\$ 15,000$ to less than $\$ 25,000$; OR $=2.90$, CI $2.801-3.010$ for $\$ 25,000$ to less than $\$ 35,000 ; \mathrm{OR}=2.15$, CI $2.075-2.216$ for $\$ 35,000$ to less than $\$ 50,000$; all compared to the highest income category at greater than $\$ 50,000$ ), having lower education than the highest level $(\mathrm{OR}=1.28$, CI 1.234 1.335 for did not graduate high school; $\mathrm{OR}=1.14$, CI 1.107 1.171 for graduated high school; OR=1.25, CI 1.214-1.284 for attended college or technical school; all compared to graduated from college or technical school), lacking health insurance $(\mathrm{OR}=5.21$, CI 5.086-5.341), having a disability $(\mathrm{OR}=2.76, \mathrm{CI} 2.695-2.825)$ and having diabetes $(\mathrm{OR}=1.27$, CI 1.226-1.316), even after controlling for all other terms in the model.
Adjusted Analysis of Change Across the Recession Period (Interaction of Race and Time)

We present predicted probabilities in Figs. 1 and 2 for vulnerable populations. These probabilities are generated from the fully adjusted model with the interaction of race/minority status and were calculated for different racial/ethnic minority groups and White adults while holding all other variables at their reference levels: the lowest income category, lowest education level, unemployed, residing in rural areas, not having disabilities or diabetes, being insured, and at the average value of all continuous model covariates.

\section{Self-Reported Fair or Poor Health Status}

Table 4 presents the fully adjusted analysis for the interaction of race/ethnicity and the Recession timeline. Changes over time across populations are expressed as the interaction between race and time and are graphically expressed in Fig. 1. Paradoxically, all groups were less likely to report fair/poor health status during the Recession period, AIAN adults were differentially affected $(p<0.05)$ compared to White adults by the Recession with regard to reporting fair/poor health when comparing prior to the Recession to the post-Recession period. Here, AIAN experienced a lower likelihood of reporting fair/poor health status from prior to the Recession to the postrecession period. Hispanic adults were also differentially affected $(p<0.05)$ as compared to White adults by the Recession when comparing the pre-Recession timeline to the postRecession. Here, Hispanic adults experienced a lower likelihood of reporting fair/poor health status in the Recession than 
Predicted Probabilities for Poor or Fair Health Status by the Recession Timeline

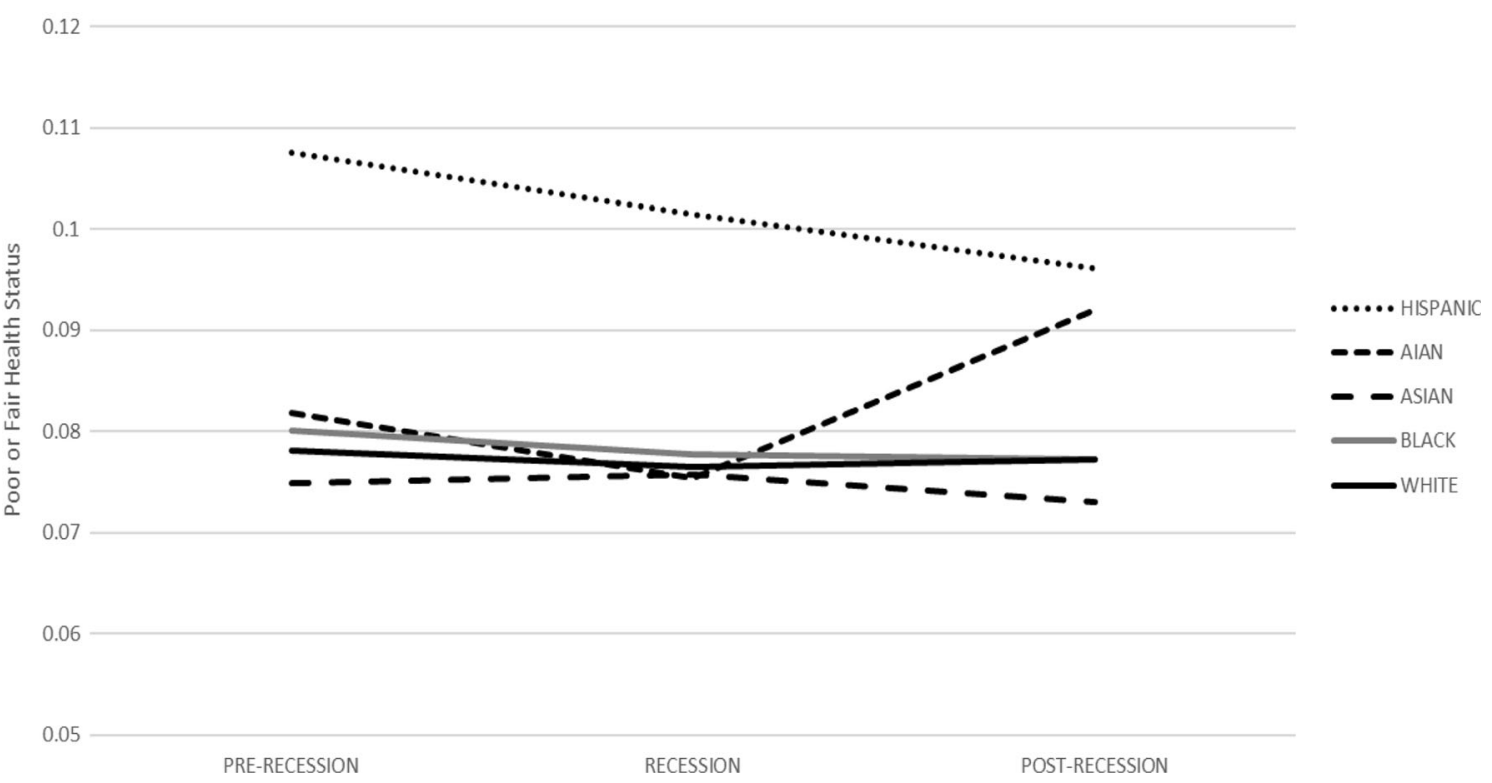

Fig. 1 Predicted probability plot for poor of fair self-reported health (interaction of recession time-frame and race/ethnicity)

in the pre-Recession. However, Hispanic adults experienced a higher likelihood of reporting fair/poor health than did White adults. No other differences (with regard to interactions) were found, after adjusting for all other terms in the model.

\section{Self-Reported Forgone Medical Care in the Past 12 Months} Due to Cost

Table 4 and Fig. 2 present the fully adjusted analysis for the interaction of race/ethnicity and the Recession timeline. When examining changes over time across populations (the interaction between race and time), AIAN adults were differentially affected $(p<0.05)$ by the Recession timeline as compared to
White adults with regard to forgone medical care when comparing the pre-Recession timeline to the Recession. Here, the likelihood of reporting poor/fair health status was lower among AIAN adults from prior to the Recession to the Recession. No other differences (with regard to interactions) were found after controlling for all other terms in the model.

\section{Discussion}

Racial and ethnic minority adults (except for Asian adults) were adversely affected by low income, low education, being uninsured, and having higher unemployment rates than White

Predicted Probabilities for Forgone Medical Care (due to cost) by the Recession Timeline

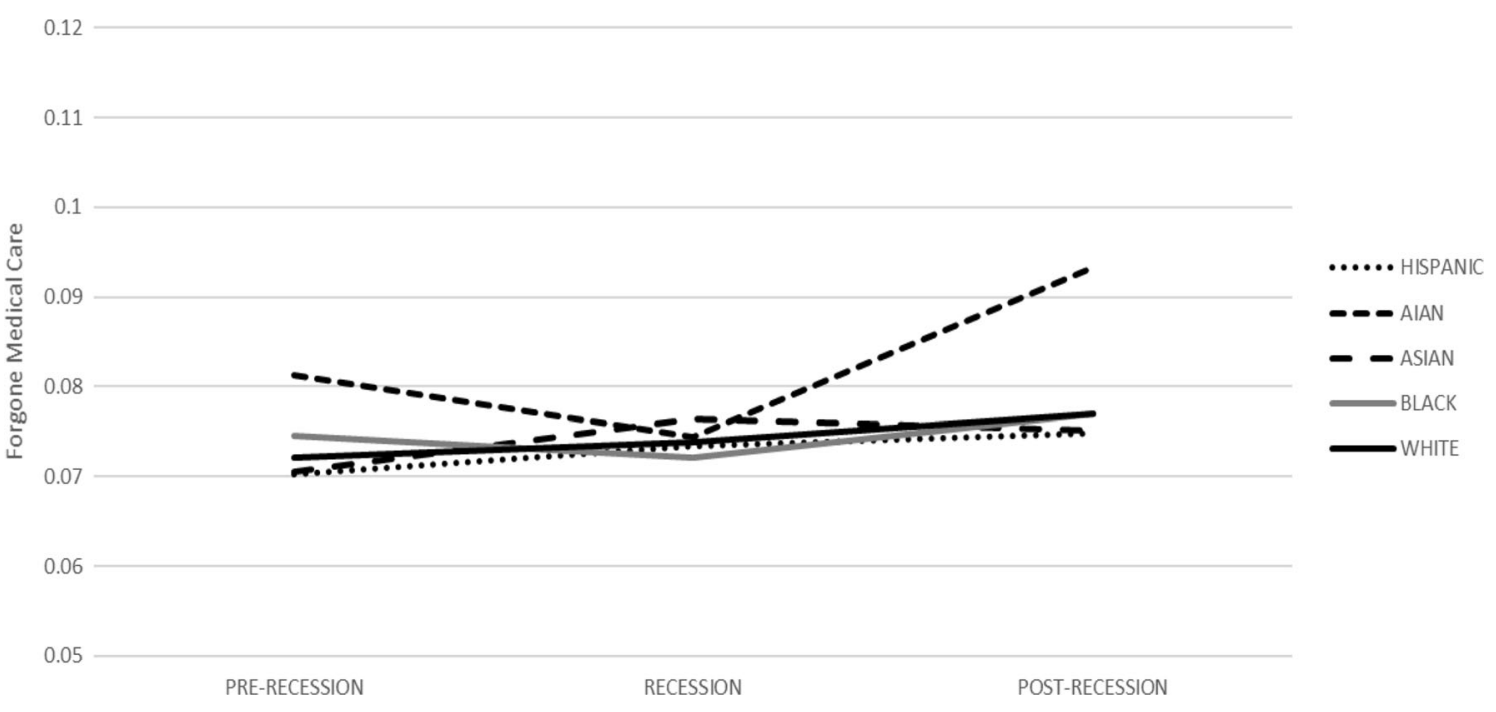

Fig. 2 Predicted probability plot for forgone medical care (interaction of Recession time-frame and race/ethnicity) 
Table 4 Change in health status and forgone medical care among working age adults across the Recession period, 2004-2010

\begin{tabular}{|c|c|c|c|c|}
\hline & \multicolumn{2}{|c|}{ Fair/poor health status } & \multicolumn{2}{|c|}{ Foregone medical care } \\
\hline & Estimate & SE & Estimate & SE \\
\hline Intercept & -0.521 & 0.037 & -1.158 & 0.036 \\
\hline \multicolumn{5}{|l|}{ Fixed effects } \\
\hline \multicolumn{5}{|l|}{ Race } \\
\hline Hispanic & 0.352 & 0.019 & -0.028 & 0.019 \\
\hline AIAN & 0.049 & 0.039 & 0.130 & 0.038 \\
\hline Asian & -0.046 & 0.037 & -0.025 & 0.039 \\
\hline Black & -0.016 & 0.019 & 0.041 & 0.018 \\
\hline White (ref.) & - & & - & \\
\hline \multicolumn{5}{|l|}{ Time period } \\
\hline Pre (ref.) & - & & - & \\
\hline During & -0.024 & 0.019 & 0.025 & 0.020 \\
\hline Post & -0.013 & 0.023 & 0.070 & 0.022 \\
\hline \multicolumn{5}{|l|}{ Time-period $\times$ race } \\
\hline Pre $\times$ White & - & & & - \\
\hline During $\times$ White & - & & & - \\
\hline Post $\times$ White & - & & & - \\
\hline \multicolumn{5}{|l|}{ Pre $\times$ Hispanic } \\
\hline During $\times$ Hispanic & -0.042 & 0.026 & 0.021 & 0.026 \\
\hline Post $\times$ Hispanic & -0.113 & 0.029 & -0.003 & 0.029 \\
\hline Pre $\times$ AIAN & - & & - & \\
\hline During $\times$ AIAN & -0.065 & 0.052 & -0.122 & 0.051 \\
\hline Post $\times$ AIAN & 0.142 & 0.064 & 0.081 & 0.064 \\
\hline \multicolumn{5}{|l|}{ Pre $\times$ Asian } \\
\hline During $\times$ Asian & 0.036 & 0.051 & 0.063 & 0.059 \\
\hline Post $\times$ Asian & -0.015 & 0.056 & -0.0003 & 0.055 \\
\hline \multicolumn{5}{|l|}{ Pre $\times$ Black } \\
\hline During $\times$ Black & 0.027 & 0.026 & 0.036 & 0.026 \\
\hline Post $\times$ Black & 0.018 & 0.030 & -0.025 & 0.029 \\
\hline
\end{tabular}

Note: Italicized data indicates significant $\leq 0.05$ ( $p$ value)

Fully adjusted analysis controls for sex, age, income, education, insurance status, employment, rurality, disability, diabetes status, state poverty rate and state unemployment rate, the Recession time-frame, and the interaction of race by recession time frame

adults throughout 2004-2010. In particular, Hispanic and AIAN adults faced severe disparities followed by Black adults. This is in contrast to White and Asian adults who were relatively less affected by these key social determinants of health. Asian individuals were less affected by the Recession relative to other groups, which may be reflective of measured differences across income, education, and insurance status. For example, Asian adults had incomes higher than that of all other racial and ethnic groups prior to and during the Recession [41, 42]. In addition, half of Asian American adults had at least a bachelor's degree (higher than White individuals at approximately $33 \%$ ) and the vast majority of Asian adults (approximately $86 \%$ ) had a high school diploma or higher education [43]. Furthermore, Asian individuals had lower levels of being uninsured than all other racial and ethnic groups except for White individuals in 2011 and 2012 [44]. Thus, improvements with regard to these key social determinants of health and access to health care are important factors to consider for policy makers.

There were differential effects across racial groups when compared to the pre-Recession time period of 2004-2007 for both self-reported health status and reporting forgone medical care in the past 12 months due to cost. We measured changes from prior to the Recession to after the Recession; however, AIAN adults experienced a lag (i.e., greater change from the Recession to the Recovery) where a sharp rise in fair/poor health status (from $22 \%$ in 2008 to $26 \%$ in 2010) was measured from the Recession to the Recovery. This is also true for forgone medical care, where the rate of reporting forgone medical care rose to approximately $28 \%$ in 2010 from $23 \%$ in 2008 . Thus, AIAN adults were particularly affected by the Recession. However, among all racial and ethnic groups, the rate of reporting forgone medical care was higher in 2010 versus 2004. Differences in forgone medical care across the Recession are consistent with previous research that identifies drops in utilizing medical services among minority and White adults including visits to physicians and inpatient visits [45].

Our analysis adjusts for spatiotemporally clustered events (separated into three periods, pre-Recession, Recession, and Recovery) and across seven years of study. Identifying potential sources for clusters of events is a common theme in epidemiological investigations [46], However, we include potential environmental/contextual factors for their potential moderating effect on the outcomes of interest. In addition, we have included several years of observation leading up to the Recession in an attempt to improve our "inferential power" regarding our conclusions ([47], p. 484).

Moving forward, researchers must identify policies that may serve to lessen the burden of economic downturns. Investigations into state policies should be conducted to determine what, if any, safety nets or coverage options may make a difference for individuals suffering throughout these economic times. In particular, investigations into whether different Medicaid policies for individuals including parents and historically uncovered childless adults [48] may lessen forgone medical care is of key interest to policy makers. The passing of the Affordable Care Act includes plans to expand Medicaid eligibility to millions of vulnerable individuals, as measured through annual income levels for eligibility. Understanding if and how such state policies affect vulnerable individuals' merits further research.

\section{Limitations}

The strength of using the BRFSS data is in the ability to identify race/ethnicity into more than the widely used White, 
Black, Hispanic, and other. Using data from 2004 to 2010, allows us to identify trends across time. This includes a period spanning before the Recession, up to the Recession, during and into the economic Recovery. Such data allow us to identify differences between race/ethnicity and within race across rurality. Our data contain unlinked individuals (not the same across time as with a longitudinal design). The data used in this analysis is cross-sectional in nature; however, we used several consecutive years of data to identify trends across time. In addition, the data cannot be linked from year to year based on the same individuals. Identifying change over time for specific persons is outside the scope of this analysis. However, the objective was to assess changes in estimates for racial and ethnic groups and not specific individuals over time.

\section{Conclusions}

The Great Recession affected the health and utilization of health care for both racial and ethnic minority and White adults; however, racial and ethnic minority populations experienced greater burden than did White adults. Understanding what happened to millions of Americans throughout the Recession is a critical step in the process of identifying targets for future policy makers and researchers. The Affordable Care Act (2010) has measures that may benefit millions of vulnerable individuals in need of medical care, but who may forgo such care due to cost. Understanding whether more generous Medicaid eligibility for working-age adults can lessen accessibility gaps in medical care remains to be seen. Furthermore, the importance of having safety net providers and/or paths to medical insurance for vulnerable individuals (e.g., Medicaid) losing employer-sponsored health insurance during economic downturns [49] is in need of further study.

Conflict of Interest All authors declare that they have no conflict of interest.

Informed Consent All procedures followed were in accordance with the ethical standards of the responsible committee on human experimentation (institutional and national) and with the Helsinki Declaration of 1975 , as revised in 2000 (5). Informed consent was obtained from all patients for being included in the study.

Animal Studies No animal or human studies were carried out by the authors for this article.

\section{References}

1. US Department of Labor, Bureau of Labor Statistics (BLS (a)). BLS spotlight on statistics: The Recession of 2007-2009. 2012; Available at: http://www.bls.gov/spotlight/2012/recession/pdf/recession_bls_ spotlight.pdf (Accessed December 16, 2012).
2. US Department of Labor, Bureau of Labor Statistics (BLS (b)). Labor Force Statistics from the Current population Survey: Annual average unemployment rate, civilian labor force 16 years and over (percent). Last updated March 9, 2012). 2012; Available at: http://www.bls.gov/ cps/prev_yrs.htm (Accessed December 14, 2012).

3. US Department of Labor and the US Bureau of Labor Statistics. Labor Force Characteristics by Race and Ethnicity, 2007. Report 1005. September 2008. Available at: http://www.bls.gov/cps/ cpsrace2007.pdf (Accessed December 16, 2012).

4. Desilver D. Black unemployment rate is consistently twice that of whites. Pew Research Center. Available at: http://www.pewresearch. org/fact-tank/2013/08/21/through-good-times-and-bad-blackunemployment-is-consistently-double-that-of-whites/ (Accessed March 22, 2014).

5. Fronstin P. Sources of health insurance and characteristics of the uninsured: analysis of the March 2012 Current Population Survey. EBRI Issue Brief. 2012;376:1-34.

6. Collins SR, Doty MM, Robertson R, Garber T. Help on the horizon: how the recession has left millions of workers without health insurance, and how health reform will bring relief - findings from The Commonwealth Fund Biennial Health Insurance Survey of 2010, The Commonwealth Fund. 2011.

7. DeNavas-Walt C, Proctor BD, Smith JC. U.S. Census Bureau, Current Population Reports, P60-238: Income, poverty, and health insurance coverage in the United States: 2009, U.S. Government Printing Office, Washington, DC, 2010. Available at: http://www.census.gov/prod/2010pubs/p60-238.pdf (Accessed January 24, 2013).

8. US Census Bureau. Income, poverty and health insurance coverage in the United States: 2010. Summary of Key Findings. Newsroom. Tuesday, September 13, 2011. Available at: http://www.census.gov/ newsroom/releases/archives/income_wealth/cb11-157.html\#tablec (Accessed January 24, 2013).

9. US Census Bureau. U.S. Census Bureau, income poverty and health insurance coverage in the United States: 2010, 2011. Available from the Assistant Secretary for Planning and Evaluation. Overview of the Uninsured in the United States: A Summary of the 2011 Current Population Survey. ASPE Issue Brief. September 2011. At: http:// aspe.hhs.gov/health/reports/2011/cpshealthins2011/ib.shtml (Accessed December 16, 2012).

10. Doty MM, Edwards JN, Holmgren AL. Seeing red: Americans driven into debt by medical bills. Results from a National Survey. Issue Brief (Commonw Fund). 2005;(837):1-12.

11. Sommers A, Cunningham PJ. Medical bill problems steady for U.S. families, 2007-2010. Track Rep. 2011;28:1-5.

12. Alley DE, Lloyd J, Pagán JA, Pollack CE, Shardell M, Cannuscio C. Mortgage delinquency and changes in access to health resources and depressive symptoms in a nationally representative cohort of Americans older than 50 years. Am J Public Health. 2011;101(12): 2293-8. Epub 2011 Oct 20. Available at: http://www.ncbi.nlm.nih. gov/pubmed/22021301 (Accessed August 14, 2012).

13. Deaton A. The financial crisis and the well-being of Americans. Oxf Econ Pap. 2012;64(1):1-26.

14. Modrek S, Cullen MR. Health consequences of the 'Great Recession' on the employed: evidence from an industrial cohort in aluminum manufacturing, Social Sci Med. 2013;92: 105-13, ISSN 0277-9536, doi: 10.1016/j.socscimed.2013.04.027.

15. Pollack CE, Lynch J. Health status of people undergoing foreclosure in the Philadelphia region. Am J Public Health. 2009;99(10):1833-9.

16. Lasser KE, Himmelstein DU, Woolhandler S. Access to care, health status, and health disparities in the United States and Canada: results of a cross-national population-based survey. Am J Public Health. 2006;96(7):1300-7.

17. Braveman PA, Cubbin C, Egerter S, Williams DR, Pamuk E. Socioeconomic disparities in health in the United States: what the patterns tell us. Am J Public Health. 2010;100 Suppl 1:S186-96. 
18. Miranda J, Duan N, Sherbourne C, Schoenbaum M, Lagomasino I, Jackson-Triche M, et al. Improving care for minorities: can quality improvement interventions improve care and outcomes for depressed minorities? Results of a randomized, controlled trial. Health Serv Res. 2003;38(2):613-30. PubMed PMID: 12785564; PubMed Central PMCID: PMC1360906.

19. Centers for Disease Control \& Prevention (CDC). 2011 National Diabetes Fact Sheet. 2011; Available at: http://www.cdc.gov/ diabetes/pubs/estimates11.htm.

20. Taylor CA, Leim KS, Fuqua DR, Johnson CA. A Diabetes Prevention Assessment Tool For American Indians. Preventing Chronic Disease. 2005;2(4), Available at: http://www.cdc.gov/pcd/ issues/2005/oct/05 0015.htm [Accessed June 1, 2009].

21. Mead H, Cartwright-Smith L, Jones K, Ramos C, Siegel B, Woods K. Racial and Ethnic Disparities in US Health Care: A Chartbook. March 2008. The Commonwealth Fund. Pub. no. 1111. Available at: http://www.commonwealthfund.org/usr_doc/Mead racialethnicdisparities chartbook 1111.pdf (Accessed December 16, 2012).

22. Key Facts about the Uninsured Population. Sep 26, 2013. Available at: http://kff.org/uninsured/fact-sheet/key-facts-about-the-uninsuredpopulation/ (Accessed March 27, 2014).

23. McLeroy KR, Bibeau D, Steckler A, Glanz K. An ecological perspective on health promotion programs. Health Educ Q. 1988;15(4): 351-77. Review.

24. Solar O, Irwin A. A conceptual framework for action on the social determinants of health. Social Determinants of Health Discussion. Paper 2 (Policy and Practice). 2010. [Accessed 10.19.2012]. Available at: http://www.who.int/sdhconference/resources/ ConceptualframeworkforactiononSDH_eng.pdf.

25. Probst JC, Moore CG, Glover SH, Samuels ME. Person and place: the compounding effects of race/ethnicity and rurality on health. Am J Public Health. 2004;94(10):1695-703. PubMed PMID: 15451735; PubMed Central PMCID: PMC1448519.

26. Glover S, Moore CG, Samuels ME, Probst JC. Disparities in access to care among rural working-age adults. J Rural Health. 2004;20(3): 193-205.

27. Ryan CL, Siebens J. Current population reports: educational attainment in the United States: 2009: population characteristics. 2012. Available at: http://www.census.gov/prod/2012pubs/p20-566.pdf (Accessed December 16, 2012).

28. Liao Y, Bang D, Cosgrove S, Dulin R, Harris Z, Taylor A, et al. Surveillance of health status in minority communities - racial and ethnic approaches to community health across the U.S. (REACH U.S.) Risk Factor Survey, United States, 2009. MMWR Surveill Summ. 2011;60(6):1-44.

29. Kutner M, Greenberg E, Jin Y, Paulsen C. The Health Literacy of America's Adults: Results From the 2003 National Assessment of Adult Literacy (NCES 2006-483). U.S. Department of Education. Washington, DC: National Center for Education Statistics; 2006.

30. DeNavas-Walt C, Proctor BD, Smith JC. Income, poverty, and health insurance coverage in the United States: 2010. US Census Bureau. Current population reports: consumer income. 2011; 60-239. Available at: http://www.census.gov/prod/2011pubs/p60-239.pdf (Accessed June 20, 2014).

31. Pollack CE, Cubbin C, Sania A, Hayward M, Vallone D, Flaherty B, et al. Do wealth disparities contribute to health disparities within racial/ethnic groups? J Epidemiol Community Health. 2013;67(5): 439-45. doi:10.1136/jech-2012-200999. Epub 2013 Feb 20. PubMed PMID: 23427209; PubMed Central PMCID: PMC3686361.

32. Kaplan GA. Economic crises: some thoughts on why, when and where they (might) matter for health — a tale of three countries. Soc
Sci Med. 2012;74(5):643-6. doi:10.1016/j.socscimed.2011.12.013. Epub 2011 Dec 28. PubMed PMID: 22209592.

33. Centers for Disease Control and Prevention (CDC). Behavioral risk factor surveillance system survey data. Atlanta, Georgia: U.S. Department of Health and Human Services, Centers for Disease Control and Prevention, 2000-2011.

34. Centers for Disease Control and Prevention (CDC). Racial/ethnic disparities in self-rated health status among adults with and without disabilities - United States, 2004-2006. MMWR Morb Mortal Wkly Rep. 2008;57(39):1069-73.

35. LeCook B, McGuire TG, Zaslavsky AM. Measuring racial/ethnic disparities in health care: methods and practical issues. Measuring and analyzing health care disparities (special issue). Health Serv Res. 2012;47(3):1232-54. II.

36. Office of Minority Health. Diabetes and African Americans. United States Department of Health and Human Services. Available at: http://minorityhealth.hhs.gov/templates/content.aspx?ID=3017 (Accessed May 2, 2013).

37. Office of Minority Health. Diabetes and American Indians/Alaska Natives. United States Department of Health and Human Services. Available at: http://minorityhealth.hhs.gov/templates/content.aspx? $l v l=2 \& l v l I D=52 \& I D=3024$ (Accessed May 2, 2013).

38. US Census Bureau. Current population survey: annual social and economic supplements. 2010 \& 2011.

39. Urban Institute and Kaiser Commission on Medicaid and the Uninsured. (2012) Poverty rate by race/ethnicity, states (2010 2011), U.S. (2011). Available at: http://www.statehealthfacts.org/ comparetable.jsp ind $=14 \& \mathrm{cat}=1 \& \mathrm{sub}=2 \& \mathrm{yr}=274 \&$ ty $\mathrm{p}=2$ (Accessed August 8, 2012).

40. US Bureau of Labor Statistics (BLS (f)). Bureau of Labor Statistics Local Area Unemployment Rates for states, 2003-2011. Available at: http://www.bls.gov/lau/\#tables (Accessed 11.28.2012).

41. DeNavas-Walt C. (2010). Income, poverty, and health insurance coverage in the United States (2005). DIANE Publishing.

42. Pew Research Center. Asian-Americans lead all others in household income. Available at: http://www.pewresearch.org/daily-number/ asian-americans-lead-all-others-in-household-income/ (Accessed June 15, 2014).

43. US Department of Health \& Human Services, Office of Minority Health. Asian American profile. Available at: http://minorityhealth.hhs. gov/templates/browse.aspx?lvl=2\&lvlID=53 (Accessed June 20, 2014).

44. DeNavas-Walt C, Proctor BD, Smith JC. U.S. Census Bureau, Current population reports, P60-245, income, poverty, and health insurance coverage in the United States: 2012, U.S. Government Printing Office, Washington, DC, 2013. Available at: http://www. census.gov/prod/2013pubs/p60-245.pdf (Accessed June 20, 2014).

45. Mortensen K, Chen J. The great recession and racial and ethnic disparities in health services use. JAMA Intern Med. 2013;173(4): 315-7. doi:10.1001/jamainternmed.2013.1414.

46. Cromley EK, McLafferty SL. GIS and public health. Chapter 6: analyzing environmental hazards. New York: The Guilford Press; 2002. p. $158-87$.

47. Shadish WR, Cook TD, Campbell DT. Experimental and quasiexperimental designs for generalized causal inference. Chapter 14: A critical assessment of our assumptions. 2002; 456-504.

48. Sommers BD, Kenney GM, Epstein AM. New evidence on the Affordable Care Act: coverage impacts of early Medicaid expansions. Health Aff (Millwood). 2014;33(1):78-87. doi:10.1377/ hlthaff.2013.1087. PubMed PMID: 24395938.

49. Felland LE, Grossman JM, Tu HT. Key findings from HSC's 2010 site visits: health care markets weather economic downturn, brace for health reform. Issue Brief Cent Stud Health Syst Change. 2011;135:1-8. 